\title{
CARACTERÍSTICAS DE LA PUBLICIDAD EN LAS REDES SOCIALES: COCA-COLA EN TUENTI
}

\section{ADVERTISING CHARACTERISTICS IN SOCIAL NETWORKS: COCA- COLA IN TUENTI}

\author{
Lourdes Sánchez Martín: ${ }^{1}$ Universidad de Granada (España)
}

\section{RESUMEN}

El término Web 2.0 fue acuñado por Tim O`Reilly para referirse a la "red como plataforma, que se extiende a todos los equipos que están conectadas a la misma; las aplicaciones Web 2.0 son aquellas que consiguen las ventajas más intrínsecas de la plataforma: presentando el software como un servicio de actualidad de forma continua y que mejora a medida que más personas lo utilizan, consumiendo y remezclando datos de múltiples fuentes, incluyendo también a usuarios individuales que al realizar su aportación y sus datos permiten que otros a su vez los utilicen, creando así efectos de red a través de una arquitectura de la participación"².

\section{Palabras Clave: Publicidad, Redes Sociales, Coca Cola}

\section{ABSTRACT}

The term Web 2.0 was coined by Tim O'Reilly to refer to the "network as a platform, which extends to all the computers that are connected to it; Web 2.0 applications are those that achieve the most intrinsic advantages of the platform: presenting the software as a topical service continuously and improving as more people use it, consuming and remixing data from multiple sources, including users Individuals that make their contribution and their data allow others to use them, creating network effects through an architecture of participation

\section{Key Words: Advertising, Social Networks, Coca Cola}

\footnotetext{
${ }^{1}$ Lourdes Sánchez Martín Licenciada en Comunicación Audiovisual y Licenciada en Filosofía por la Universidad de Granada. Ha realizado el Máster en Traducción y Mediación Lingüística de las Lenguas Española y Alemana, y el Máster en Dirección en Comunicación. Investigadora en Comunicación audiovisual, es miembro del grupo de investigación CiberAV "Cibercultura, procesos comunicativos y medios audiovisuales" de la Universidad de Granada, y forma parte del Grupo Comunicar, de la Sociedad Española de Lenguas Modernas y de la Asociación española de investigación de la Comunicación (AE-IC). Es autora de algunos capítulos de libros, de varios artículos en revistas de Comunicación y de diversas comunicaciones en Actas de Congresos internacionales.

2 O'Reilly, T. "What is Web 2.0: Design Patterns and Business Models for the Next Generation of Software". 2005. http://www.oreillynet.com/lpt/a/6228/
} 


\section{Cómo citar el artículo:}

\section{Lourdes Sánchez Martín. CARACTERÍSTICAS DE LA PUBLICIDAD EN LAS REDES SOCIALES: COCA-COLA EN TUENTI. Revista de Ciencias de la Comunicación e Información. (Diciembre 2011). Año XXV (28), 8-16 ISSN: 0213-070-X. Recuperado: \\ http://www.revistaccinformacion.net/ARTICULOS/2011\%20Paula\%20Requeijo/2011\%20Car acter\%C3\%ADsticas\%20de\%20la\%20publicidad...\%20S\%C3\%A1nchez\%20Mart\%C3\%ADn. pdf}

\section{Introducción}

Desde su aparición, la Web 2.0 ha propiciado la aparición de numerosas plataformas y posibilitado nuevos modos de relación entre internautas a través de la red de redes. En España, según el "Il Estudio sobre Redes Sociales en Internet" por IAB Spain (Noviembre de 2010) el $70 \%$ de los individuos que se conectan a Internet son usuarios de redes sociales, aumentando esta proporción casi un $20 \%$ con respecto a 2009 (51\%). Tres de cada cuatro usuarios se conectan diariamente a sus perfiles. Los usuarios que no utilizan redes sociales según este último estudio se reducen al $30 \%$.

Como demuestran estos datos, el éxito que han alcanzado estas plataformas es manifiesto. Por ello, pretendemos a lo largo de este estudio exponer cronológicamente la aparición de algunas de estas plataformas hasta nuestros días, para adentrarnos a continuación en la red social Tuenti, dada su alta notoriedad entre los adolescentes y jóvenes españoles y, más concretamente, en las características propias que la página de marca de Coca-Cola presenta en esta red.

\section{Cronología de las redes sociales}

Las redes sociales más destacadas en la actualidad son plataformas tan conocidas como Facebook o Tuenti. Sin embargo, estas comunidades virtuales tan utilizadas hoy en día no son tan recientes como parece. La primera red social apareció en 1997 con el nombre SixDegrees ${ }^{4}$. Entre sus funcionalidades destacaba la posibilidad de crear perfiles y listas de amigos, permitiendo a los usuarios navegar por dichas listas a partir de 1998. Esta plataforma se autopromocionaba como una herramienta creada con el objetivo de ayudar a las personas a conectarse y comunicarse entre sí. En el año 2000 dejó de prestar su servicio al no encontrar una formula de negocio sostenible.

Tras SixDegrees, en la década de los 90 fueron otras muchas redes las que se dieron a conocer: Classmates. com $^{5}$ permitía a los usuarios afiliarse a un centro de estudios y conocer a otros en la misma situación; Asian Avenue ${ }^{6}$ o MiGente $^{7}$, la creación de perfiles personales o profesionales, en donde se podía conectar con

\footnotetext{
${ }^{3}$ IAB Spain. "III Estudio sobre Redes Sociales en Internet", noviembre de 2010, pp. 1-74.

${ }^{4}$ http://www.sixdegrees.org/

5 http://www.classmates.com/

6 http://www.asianave.com/

7 http://www.migente.com/
} 
amigos sin ni siquiera solicitar la aprobación previa por parte de los demás (común en la actualidad).

En 2001 aparece Ryze.com ${ }^{8}$, red social con fines empresariales que nunca adquirió la suficiente popularidad. A esta red le siguieron otras como Tribe.net ${ }^{9}$, que logró penetrar entre un target muy definido; LinkedI $n^{10}$, muy popular en la actualidad y centrada en perfiles donde los usuarios explicitan sus propias competencias curriculares y profesionales; Friendster ${ }^{11}$ que tras alcanzar popularidad, fracasó. Como señala Del Moral ${ }^{12}$, en la creación de todas estas redes sociales subyace la implantación de la teoría sociológica de los "seis grados de separación".

En 2003 aparece ya una diversidad de comunidades con múltiples objetivos. En España, destaca eConozco, primera red social de negocios e hispana que no alcanzó éxito (incluso era desconocida para gran parte de los internautas) y que, posteriormente, se convirtió en Xing ${ }^{13}$. En Estados Unidos cobra relevancia la plataforma MySpace ${ }^{14}$, centrada en contenidos musicales y el contacto con los amigos.

Solo un año después, aparecen dos redes sociales de relevancia y con un mismo objetivo: Orkut, creada por un ingeniero de Google logró alcanzar un gran éxito, que menguó tiempo después y Facebook, utilizada por millones de usuarios de todo el mundo.

Tras la creación de estas redes, han aparecido a lo largo de los últimos años otras muchas, intentando responder a todos los propósitos y temáticas posibles, desde conectar a enfermos crónicos, Qoolife ${ }^{15}$; expresar el interés por la lectura, Librofilia $^{16}$; conectar a viajeros, Couchsurfing ${ }^{17}$, encontrar pareja, Match.com ${ }^{18} 0$ Meetic.com ${ }^{19}$, etc. Debido a su variedad, el público se diversifica. No obstante, las redes sociales que han alcanzado una mayor popularidad que mantienen en la actualidad son:

- Facebook ${ }^{20}$, que continúa conectando a millones de usuarios de diferentes países y cuya comunicación gira en torno al perfil personal. Ha posibilitado una democratización publicitaria a través de la "venta" de pequeños banners

\footnotetext{
${ }^{8}$ http://ryze.com/

${ }^{9}$ http://www.tribe.net/

${ }^{10}$ http://es.linkedin.com/

${ }_{11}^{11}$ http://www.friendster.com/

${ }^{12}$ Del Moral, J. A. Redes sociales y wikis. En: Rojas Orduña, Octavio. (Coord.). Web 2.0: Manual (no oficial) de uso. Madrid: ESIC, 2007, pp. 17-60.

${ }^{13}$ https://www.xing.com/es

${ }^{14}$ http://www.myspace.com/

${ }^{15}$ https://qoolife.com/

${ }^{16}$ http://www.librofilia.com/

${ }^{17}$ http://www.couchsurfing.org/

${ }^{18} \mathrm{http}: / /$ www.match.com

${ }^{19}$ http://www.meetic.com

${ }^{20}$ http://www.facebook.com
} 
a un bajo precio. Mediante la comercialización de estos espacios publicitarios y la segmentación tan precisa que puede ofrecer a los anunciantes.

- Tuenti ${ }^{21}$, red social horizontal de procedencia española. Sus usuarios son principalmente los adolescentes y jóvenes españoles.

- Twitter $^{22}$, red social de nanoblogging, permite una comunicación limitada por un número de caracteres. Acapara a millones de usuarios, desde políticos, programas de televisión, radio, escritores, etc., dada su eficiencia comunicativa a través de mensajes directos, rápidos y personalizados.

Tuenti presenta unas particularidades especiales, razón por la que el presente análisis se centrará en esta plataforma. Fue creada en el año 2006 por Zaryn Dentzel con el fin de conectar a estudiantes universitarios. Tras no alcanzar el éxito entre este target, permitió entonces la entrada a usuarios por invitación con la intención de transmitir cierta exclusividad. Entre sus funcionalidades destacan: la creación del perfil propio, la posibilidad de contactar con amigos a través de listas de contactos y la publicación de diferentes tipos de contenidos (audiovisuales, imágenes, mensajes, etc.).

A pesar de dirigirse en un primer momento al público universitario, entre su target destacan principalmente los adolescentes y jóvenes españoles al configurarse como la primera red social que permite el registro activo de menores a partir de los 14 años, frente al resto de redes que exigen la mayoría de edad para el acceder a la plataforma. En la actualidad, según el "Il Estudio de Redes Sociales en Internet" (noviembre de 2010) es la segunda red social con más notoriedad -62\%-, después de Facebook; la tercera más utilizada (44\%) detrás de Facebook y Youtube y con la frecuencia de uso más alta, el $38 \%$ de los usuarios aseguran que se conectan a ella varias veces al día.

En mayo de 2010 Tuenti permite por vez primera la creación de páginas de marca que se alternan con los ya usuales perfiles de los usuarios. Así los anunciantes se introducen en esta plataforma y se amplían sus posibilidades publicitarias. CocaCola es una de las primeras marcas que en el mismo mayo de 2010 se incluye en esta plataforma e inicia su perfil con la finalidad de establecer una comunicación fluida con sus seguidores.

\section{Publicidad en Tuenti: el caso Coca-Cola}

Coca-Cola es la marca que acapara a un mayor número de seguidores en la red social Tuenti. Desde sus inicios, el refresco ha logrado captar de diferentes modos la atención (banners, felicitaciones de cumpleaños personalizadas, contenidos audiovisuales, etc.) de los usuarios y aumentar exponencialmente el número personas que declaran voluntariamente su interés.

Coca-Cola ofrece en su perfil diferentes formatos que ocupan claramente un espacio determinado en la estructura de la página de marca. De este modo, podemos diferenciar seis áreas, en donde cada una de ellas se centra en un contenido

\footnotetext{
${ }^{21}$ http://www.tuenti.com

22 http://www.twitter.com
} 
particular: galería de imágenes, recoge las figuras subidas por la marca; galería de vídeos, se incluyen los contenidos audiovisuales, principalmente spots de Coca-Cola $u$ otros productos de la marca; seguidores, aparecen el nombre e imagen de los seguidores de la marca; otros enlaces, remiten a otras páginas referentes a diferentes productos o eventos; contenidos de entretenimiento, información de interés propiamente adolescente que vincula con la página web de Coca-Cola y el tablón, en donde se establece la comunicación entre los usuarios y la marca.

La zona del tablón es la que nos parece más interesante dadas sus particularidades: en ella se establece una comunicación fluida, activa y abierta al diálogo por parte de los usuarios y Coca-Cola. Mientras que en los otros contenidos la marca mantiene su preeminencia y verticalidad comunicativa, en el tablón esta relación es horizontal, variando significativamente las características y elementos propios de los contenidos publicitarios. Por ello, examinamos a continuación la especificidad de esta comunicación y propiamente de Coca-Cola en Tuenti.

\section{Características de las marcas en las redes sociales: coca-cola en tuenti}

El gran auge que han experimentado estas plataformas y, más concretamente, la página de Coca-Cola en Tuenti, se debe principalmente a las características propias y a las ventajas que se derivan de su uso. La comunicación en Internet presenta los mismos elementos que la comunicación a través de otros soportes ${ }^{23}$, aunque su funcionamiento requiere de enfoques y criterios de gestión distintos ${ }^{24}$. En las redes sociales y, particularmente, en el perfil de Coca-Cola en Tuenti podemos diferenciar los siguientes elementos:

- El emisor es, por lo general, el anunciante: Coca-Cola. Sin embargo, en Tuenti podemos comprobar que los usuarios también se convierten constantemente en emisores activos, aun cuando sus mensajes se insertan siempre dentro de las entradas establecidas por la marca. Asimismo, la marca ejerce el rol de receptor en las múltiples ocasiones que es interpelada por los internautas; los usuarios por su parte asumen igualmente dicho rol. El receptor es por tanto "múltiple"25: una comunicación colectiva dirigida a la totalidad de los seguidores de la marca y que es la que tiene una mayor presencia; una comunicación personalizada y dirigida a individuos concretos, en aquellas ocasiones en el que la marca nombra a ciertos usuarios para transmitirles una información determinada y la comunicación que los adolescentes colectivamente establecen entre ellos y con respecto a la marca.

- Según Llorente ${ }^{26}$, el mensaje es tratado siempre "desde el punto de vista corporativo o de productos y servicios". Entre las entradas emitidas por CocaCola en Tuenti, aun cuando existe siempre -de un modo directo o indirecto- una intención publicitaria subyacente, los mensajes no realizan en la mayor parte de los casos una referencia directa a su producto sino a valores añadidos que

\footnotetext{
${ }^{23}$ Calvo Fernández, S. \& Reinares Lara, P. Comunicación en Internet: Estrategias de márketing y comunicación interactiva. Paraninfo: Madrid, 2001.

${ }^{24}$ Llorente Barroso, C.; Núñez Gómez, P. \& García Guardia, M. L. "La marca en la hipermedia", Creatividad y Sociedad, 2010, no 15, pp. 2-41.

${ }^{25}$ Ibidem

${ }^{26}$ Ibidem
} 
configuran la imagen de marca. Para ello, se apela a diferentes temáticas: cine, música, deporte, otros productos, etc.

- El código: "es necesario conocer las claves de funcionamiento de Internet para poder acceder y descodificar los mensajes"27. En este caso, el acceso a los mensajes emitidos por la marca solo es posible previo registro en la red social y adscripción del usuario a la página de Coca-Cola.

- El canal es la red social Tuenti y más concretamente el perfil de la marca.

Internet y, más concretamente, las redes sociales han modificado así la relación tradicional entre anunciantes y consumidores, no solo debido a la horizontalidad del medio sino también "por la modificación de hábitos que esto conlleva y sus implicaciones para las estrategias de comunicación de las marcas" ${ }^{28}$. Entre los nativos digitales, principales seguidores de Coca-Cola en Tuenti, estos cambios son aun más pronunciados, ya que Internet y las redes sociales se han convertido para ellos "en parte integral de sus vidas y en su realidad tecnológica"29.

Estas plataformas responden en última instancia al propósito de Tim Berners-Lee, creador de la World Wide Web: un objetivo social que en ocasiones se ha visto solapado por los aspectos técnicos ${ }^{30}$. La consecución de este propósito es todavía más palpable en las redes sociales que, por sus características intrínsecas y su funcionamiento, logran establecer de un modo eficiente conexiones entre individuos. Más concretamente, en la página de Coca-Cola en Tuenti, podemos observar cómo los vínculos entre una marca y sus consumidores se estrechan. La marca se humaniza y solo así es capaz de "generar lazos afectivos en el área comercial con sus clientes y consumidores, tanto actuales como potenciales"31.

Posibilitan además una participación activa y autónoma en el proceso de comunicación por parte de ambos agentes. Son ellos los que configuran la construcción de la identidad social y la imagen de marca, los que aceptan y mantienen esa ideología o por el contrario la condenan en las redes sociales a través de la palabra, ya que los límites entre emisor y receptor tan delimitados en la publicidad convencional se disuelven. Los usuarios pueden por vez primera expresar su opinión con respecto al producto.

Por ello, las redes sociales facilitan que los anunciantes puedan conocer más que nunca a las audiencias, que exista un feedback. De este modo, Coca-Cola conoce los intereses, gustos, hábitos y modas a los de los adolescentes y los explota para captar su atención. De hecho, la marca refleja en sus comentarios estos intereses propiamente adolescentes apelando a grupos de música, obsequios, concursos,

\footnotetext{
${ }^{27}$ Ibidem

${ }^{28}$ Llorente, Op. Cit., Pág. 28

${ }^{29}$ García, F.; Portillo, J., Romo, J. \& Benito, M. Nativos digitales y modelos de aprendizaje. Universidad del País Vasco, 2008, pág. 2

${ }^{30}$ Bernal Triviño, A. I. "Influencia de las redes sociales en los medios de comunicación". En: Cabrera González, María Ángeles (Coord.). Evolución tecnológica y cibermedios. Zamora: Comunicación Social, 2010.

${ }^{31}$ Rosales, P. Estrategia digital. Cómo usar las nuevas tecnologías mejor que la competencia. Barcelona: Deusto, 2010. Pág. 87.
} 
cine, etc. Al mismo tiempo, conoce la aceptación o desagrado por parte de los usuarios, por lo que puede acotar cada vez con más claridad los temas que realmente atraen a sus seguidores. Además, estas plataformas presentan por lo general un público concreto y definido dependiendo de las funcionalidades y temática de la misma.

De este modo, Tuenti presenta ya de por sí un target concreto. En su mayor parte, el público asiduo en esta red social son los adolescentes españoles. Los contenidos publicitarios emitidos en estas redes son por ello más eficientes, en la medida en la que pueden dirigirse a su audiencia concreta adaptando los contenidos a grupos muy definidos. Coca-Cola establece de este modo una estrategia comunicativa y de marca adaptada a este público. Esto asegura cierto éxito -siempre y cuando la marca se ocupe de conocer en la mayor medida posible a su público y desarrollar la estrategia adecuada a él- ya que se tendrá así una alta afinidad con el target.

Conociendo estos datos, Coca-Cola puede seleccionar activamente las entradas que publica en la red social para "que la carga semántica de las palabras sea óptima y resuma [...] lo que pretenda decir del producto y persuadir captando la atención del receptor"32. La interactividad es otra característica propia de estos entornos que facilitan la inmediatez y personalización de los contenidos y mensajes de la marca, agilizando sustancialmente el conocimiento de los datos.

Además, los seguidores pueden a través de las páginas de marca acceder a nuevos contactos $^{33}$ con sus mismos intereses, hábitos, gustos o preferencias por un mismo producto.

El anunciante y los usuarios ejercen de guía cognitiva y consejeros ${ }^{34}$ en el grupo de pertenencia (los seguidores de Coca-Cola en Tuenti) al desarrollar el rol de influenciadores. Existe además un liderazgo de opinión en la medida en la que se "influye informalmente sobre las acciones o actitudes de otros, quienes pueden ser buscadores de opinión o meramente receptores de la misma" ${ }^{35}$ al informar positivamente sobre Coca-Cola. De hecho, se registra en esta página de marca menos del $5 \%$ de comentarios negativos con respecto al producto por parte de los propios usuarios, e incluso son ellos mismos los que aconsejan e informan de las bondades del producto.

A esto se le debe unir la función de regulación o control social ${ }^{36}$ del grupo y que en las redes sociales "neutralizan las desviaciones de comportamiento que apartan de las expectativas colectivas" ${ }^{37}$. A propósito de ello podemos encontrar en la página de Coca-Cola que los propios seguidores, no la marca, son los que neutralizan los

\footnotetext{
32 Romero Gualda, M. V. "Persuasión y sintaxis publicitaria”. En: Robles, S.; Romero, M. (Coord.). Publicidad y lengua española. Salamanca: Comunicación social, 2010, Pág. 153.

${ }^{33}$ Sluzki, C. E. La Red Social: Frontera de la practica sistémica. España: Gedisa, 1996.

${ }^{34}$ Ibidem

${ }^{35}$ Solé Moro, M. L. Los consumidores del siglo XXI. Madrid: ESIC, 2003. Pág. 88.

${ }^{36}$ Sluzki. Op. Cit.

${ }^{37}$ Madariaga Orozco, C.; Abello Llanos, R. \& Sierra García, O. Redes sociales: infancia, familia y comunidad. Barranquilla: Universidad del Norte, 2005. Pág. 32.
} 
pocos comentarios negativos de otros usuarios, desaprobando sus mensajes y no gratificando grupalmente este tipo de comentarios.

Como hemos podido ver a lo largo del presente epígrafe, el análisis de estas plataformas ayuda sin duda a conocernos a nosotros mismos y nuestra propia estructura social ${ }^{38}$. Por ello, nos parece necesario profundizar en posteriores estudios en aspectos más concretos y propios de estas comunidades, ya que nos pueden aportar datos relevantes sobre cuestiones tan importantes como la influencia que ejercen estos grupos de seguidores en el comportamiento del consumidor; el nuevo rol que asumen los usuarios frente a los contenidos publicitarios en las redes sociales; conocer hacía donde se dirigen las marcas en un futuro próximo, cuando en la actualidad la crisis publicitaria es manifiesta; dilucidar los aspectos significativos de la comunicación que se establece entre usuarios y anunciantes 0 , más concretamente, conocer cómo en estas plataformas los anunciantes se dirigen de un modo directo a los menores -como lo hace Coca-Cola en Tuenti- y las posibles consecuencias en estos nativos digitales.

\section{Conclusiones}

- Las redes sociales, al contrario de lo que normalmente se cree, no son tan recientes como parece. A pesar de que el término "Web 2.0" no fue acuñado por O`Really hasta 2004, mucho antes ya existían redes sociales como SixDegrees.

- Con la primera aparición de las redes sociales han emergido a lo largo de la última década una multiplicidad de plataformas con diversas temáticas y objetivos. Así, podemos encontrar en la actualidad redes sociales con cualquier fin.

- Las marcas y anunciantes pueden encontrar en las redes sociales un medio realmente propicio para su comunicación publicitaria, así lo refleja la página de marca de Coca-Cola en Tuenti. Las ventajas que le aporta esta red para la consecución de sus objetivos publicitarios son numerosas: un conocimiento más detallado del consumidor; microsegmentación del target, dirigiéndose a un perfil muy concreto; humanización de la marca; influencia del grupo sobre los seguidores ejerciendo una regulación y un control social, actuando como consejeros y gratificando ellos mismos aquellas opiniones positivas del producto.

- No obstante, las marcas deben ser conscientes del cambio de paradigma que han propiciado las redes sociales en el ámbito publicitario y la regularidad que exige su presencia en estas plataformas. Los elementos y las características propias de la comunicación han cambiado, así como los roles asumidos por anunciantes y usuarios.

\footnotetext{
${ }^{38}$ Walker, J. "Freshly Generated for you, and Barack Obama. How social Media represent your life", European Journal of Communication, 2009, vol. 24, pp. 451-466.
} 
- De este modo, Coca-Cola se erige como un ejemplo de anunciante que ha sabido reconocer los cambios que han propiciado las comunidades virtuales y que mantiene activa y regularmente la atención de sus seguidores en Tuenti, atendiendo la horizontalidad comunicativa.

- Resulta necesario y urgente profundizar en estas plataformas de un modo más extenso y concreto con la finalidad de conocer más detalles de las mismas, la influencia que ejercen sobre los consumidores y usuarios, los aspectos significativos de esta comunicación, así como el papel asumido por los adolescentes que, en Tuenti, son sometidos a continuos contenidos publicitarios.

\section{Referencias}

BERNAL TRIVIÑO, A. I. "Influencia de las redes sociales en los medios de comunicación". En: Cabrera González, María Ángeles (Coord.). Evolución tecnológica y cibermedios. Zamora: Comunicación Social, 2010, pp. 119-120.

CALVO FERNÁNDEZ, S. \& REINARES LARA, P. Comunicación en Internet: Estrategias de márketing y comunicación interactiva. Paraninfo: Madrid, 2001.

DEL MORAL, J. A. Redes sociales y wikis. En: Rojas Orduña, Octavio. (Coord.). Web 2.0: Manual (no oficial) de uso. Madrid: ESIC, 2007, pp. 17-60.

GARCÍA, F.; PORTILLO, J., ROMO, J. \& BENITO, M. Nativos digitales y modelos de aprendizaje. Universidad del País Vasco, 2008, pp. 1-11. http://spdece07.ehu.es/actas/Garcia.pdf

http://www.iabspain.net/wp-content/uploads/downloads/2012/04/III-Estudio-sobreredes-sociales-en-Internet.pdf

IAB Spain. "II Estudio sobre Redes Sociales en Internet", noviembre de 2010, pp. 174.

LLORENTE BARROSO, C.; NÚÑEZ GÓMEZ, P. \& GARCÍA GUARDÍA, M. L. "La marca en la hipermedia", Creatividad y Sociedad, 2010, № 15, pp. 2-41.

MADARIAGA OROZCO, C.; ABELLO LLANOS, R. \& SIERRA GARcÍA, O. Redes sociales: infancia, familia y comunidad. Barranquilla: Universidad del Norte, 2005.

O'REILLY, T. "What is Web 2.0: Design Patterns and Business Models for the Next Generation of Software". 2005. http://www.oreillynet.com/lpt/a/6228/

ROMERO GUALDA, M. V. "Persuasión y sintaxis publicitaria". En: Robles, S.; Romero, M. (Coord.). Publicidad y lengua española. Salamanca: Comunicación social, 2010, pp. 150-162.

ROSALES, P. Estrategia digital. Cómo usar las nuevas tecnologías mejor que la competencia. Barcelona: Deusto, 2010.

SLUZKI, C. E. La Red Social: Frontera de la practica sistémica. España: Gedisa, 1996.

SOLÉ MORO, M. L. Los consumidores del siglo XXI. Madrid: ESIC, 2003. 